\title{
Changing storminess? An analysis of long-term sea level data sets
}

\author{
W. Bijl ${ }^{1, *}$, R. Flather ${ }^{2}$, J. G. de Ronde ${ }^{1}$, T. Schmith ${ }^{3}$ \\ ${ }^{1} \mathrm{~N}$ ational Institute for C oastal and Marine Management, Kortenaerkade 1, 2518 AX The Hague, The Netherlands \\ ${ }^{2}$ Proudman 0 ceanographic Laboratory, Bidston O bservatory, Birkenhead, G B-M erseyside L43 7RA, United Kingdom \\ ${ }^{3}$ Danish M eteorological Institute, Lyngbyvej 100, DK-2100 Copenhagen, Denmark
}

\begin{abstract}
This paper considers the analysis of long-term observational sea level data sets within the context of a possible change in storminess over North-West Europe. Sea level variations are studied as a proxy for storminess, i.e. in the synoptic frequency band. In that band, a proxy correspondence is assumed between sea levels and wind stress, although with some damping of the highest frequencies. Trends and variability over the past $100 \mathrm{yr}$ are studied. However, a complicating factor is that many data sets include astronomical tidal influences (e.g. spring tide-neap tide cycle), which mask the signal that is of most interest in this study. Sea level data sets from stations in the coastal zones of NorthWest Europe were collected, homogenised and made free of auto-correlation. To analyse these data sets, the 'quantile analysis method' is presented. This method involves an advanced analysis technique which, on the basis of a frequency analysis, determines the roughness/smoothness of succeeding decades in relation to the complete time period of a data set. Possible storm-related trends and variations in this decadal quantity are defined by means of linear regression. Besides this main method, a time-shift variant of the quantile analysis method is applied in order to discuss the sensitivity of the obtained results. This sensitivity is also investigated with respect to the length of the time period in which a complete data set is split up. Although the analysis results show considerable natural variability on relatively short (decadal) time scales, no sign of a significant increase in storminess over N orthWest Europe is detected over the complete time period of the data sets. The results indicate a distinction between stations in the German Bight and stations in the southern part of the North Sea. In the latter area, the natural variability is more moderate and there appears to be a tendency towards a weakening of the storm activity over the past $100 \mathrm{yr}$ (not significant). Stations in the German Bight show a more enhanced natural variability on relatively short (decadal) time scales, with no indication of a weakening of the storm climate.
\end{abstract}

KEY WORDS: Climate change $\cdot$ Storminess $\cdot$ Homogenisation $\cdot$ Time series

\section{INTRODUCTION}

In the past, coastal defence structures were designed on the basis of a knowledge of the severest recorded storm event (e.g. dikes were designed to be as high as this storm event $+1 \mathrm{~m}$ ). A more scientific approach is now applied to the design of these structures (de Ronde et al. 1995). Extreme value statistics are computed for observed hydraulic and meteorological parameters such as sea level, wave height and wind, and safety standards are set for various coastal areas (depending on their economic importance). Thus estimates of the hydraulic parameters are obtained which

*E-mail: w.bijl@dlb.rws.minvenw.nl correspond to the safety standard of a specific part of the coast.

The methodology described above is also used by the oil industry to design offshore constructions. Recently however, several papers have suggested a substantial increase in wave heights in the North-East Atlantic over the past 3 or 4 decades (Carter \& Draper 1988, van Hooff 1994, Hogben 1995). This would imply that the statistically derived extreme wave height, which corresponds to the safety standard of offshore constructions, may be unsafe. Therefore the oil industry has become very concerned about the validity of the existing extreme value wave height statistics. The insurance industry, which has incurred unprecedented losses due to unusually severe storms in recent years 
(Leggett, 1993), is also concerned. As a result, the question has been raised whether the recently observed severe storms are normal events in the spectrum of storms or whether they must be understood as indicators of an increased storm-related risk.

The present paper focuses on the detection of stormrelated trends and variations in long-term observational sea level data sets, in order to give a wellfounded contribution to the question of changing storminess over N orth-West Europe. Sea level variations are studied because, in the synoptic frequency band, a proxy correspondence can be assumed between sea levels and wind stress. In Section 2, the sea level data sets are described. In addition, the selection procedures which have been carried out in order to make these data sets suitable for trend analysis are outlined. Section 3 describes the analysis method which is used to detect storm-related trends and variations in the data sets described in Section 2. The results of applying this method are presented in Section 4. Finally, Section 5 contains some discussion and concluding remarks.

\section{DATA}

The observational sea level data sets used in this study are obtained from measurement stations in coastal areas of North-West Europe (Fig. 1). A general description of these data sets is presented in this section, together with selection methods to make these

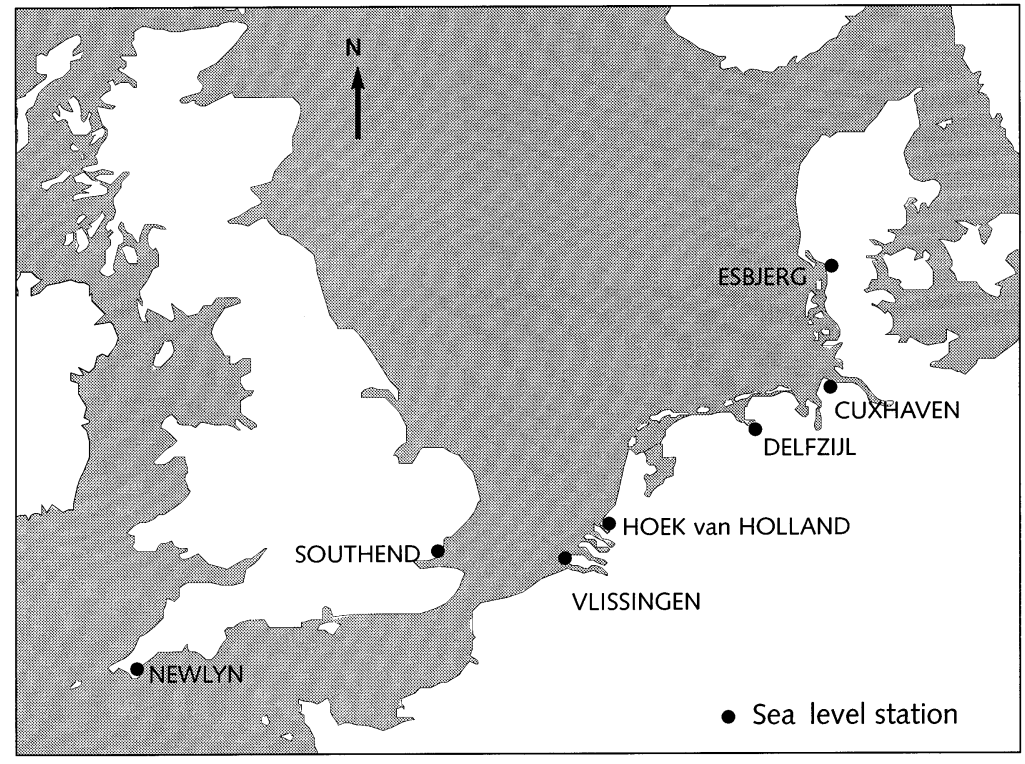

Fig. 1. Position of the sea level measurement stations in coastal areas of N orthWest Europe inhomogeneous, auto-correlated data sets suitable for trend analysis.

The sea level measurement stations shown in Fig. 1 provide observational sea level data sets of 5 kinds:

\subsection{High-water set-up data: Vlissingen, Hoek van Holland, Delfzijl}

The data sets of this type contain the storm-related set-up at high tides, which is by definition the observed high-water level minus the corresponding astronomical water level at high tide, regardless of a time shift. This means that, with a lunar tide period of 12 h 25 min, approximately 2 observations $d^{-1}$ are available. The time periods which are covered by these data sets are given in Table 1.

To construct these high-water set-up data sets, for each station the astronomical water levels were computed and analysed in chunks of $10 \mathrm{yr}$ by means of a tidal analysis based on the culmination method (de Ronde 1984). The culmination method is a tidal analysis method which analyses and predicts time and height of water levels at high and low tide. The time of culmination of the moon is taken as the starting point. Given a certain culmination time of a particular tide gauge, a non-linear multiple relation is derived between time and height of water levels at high and low tide and the declination and parallax of the moon. Subtracting the obtained astronomical water levels from the observed high-water levels ensures that the resulting data sets are not affected by changes in the hydraulic regime, either gradual or abrupt (Dillingh et al. 1993).

Therefore, within the context of the present paper, these data sets are very valuable because they reflect only storm-related water level variations. However, the computation of astronomical water levels on the basis of the culmination method involves an enormous amount of work.

In this study, high-water set-up data sets are only available for the Dutch coastal stations Vlissingen, Hoek van Holland and Delfzijl, mainly because for these stations the computation of astronomical water levels has already been performed within the context of a study concerning the 'design levels' along the Dutch coast (de Ronde et al. 1995). In addition, for the remaining sea level stations, too little information is available to construct the astronomical data sets on the basis of the culmination method. 
Table 1 . Time periods covered by the sea level data sets

\begin{tabular}{|c|c|c|c|c|c|}
\hline & $\begin{array}{l}\text { High-water } \\
\text { set-up }\end{array}$ & High water & $\begin{array}{c}\text { Daylight } \\
\text { high water }\end{array}$ & $\begin{array}{l}\text { Maximum } \\
\text { high water }\end{array}$ & $\begin{array}{c}\text { Hourly } \\
\text { water level }\end{array}$ \\
\hline $\begin{array}{l}\text { Newlyn, } \\
\text { UK }\end{array}$ & & & & & $\begin{array}{l}\text { J an 1, 1916- } \\
\text { Dec 31, } 1995\end{array}$ \\
\hline $\begin{array}{l}\text { Southend, } \\
\text { UK }\end{array}$ & & & & & $\begin{array}{l}\text { Mar 1, 1929- } \\
\text { Dec 31, } 1980\end{array}$ \\
\hline $\begin{array}{l}\text { Vlissingen, } \\
\text { The Netherlands }\end{array}$ & $\begin{array}{l}\text { J an } 1,1882- \\
\text { Dec 31, } 1993\end{array}$ & $\begin{array}{l}\text { J an } 1,1882- \\
\text { Dec } 31,1993\end{array}$ & & & \\
\hline $\begin{array}{l}\text { Hoek van Holland, } \\
\text { The N etherlands }\end{array}$ & $\begin{array}{l}\text { J an 1, 1888- } \\
\text { Dec 31, } 1993\end{array}$ & $\begin{array}{l}\text { Jan } 1,1888- \\
\text { Dec 31, } 1993\end{array}$ & & & \\
\hline $\begin{array}{l}\text { Delfzijl, } \\
\text { The Netherlands }\end{array}$ & $\begin{array}{l}\text { J an 1, 1882- } \\
\text { Dec 31, } 1993\end{array}$ & $\begin{array}{l}\text { Jan 1, 1882- } \\
\text { Dec 31, } 1993\end{array}$ & $\begin{array}{l}\text { J an } 1,1827- \\
\text { Dec 31, } 1993\end{array}$ & & \\
\hline $\begin{array}{c}\text { Cuxhaven, } \\
\text { Germany }\end{array}$ & & $\begin{array}{l}\text { J an 1, 1843- } \\
\text { Dec 31, } 1992\end{array}$ & & & \\
\hline $\begin{array}{l}\text { Esbjerg, } \\
\text { Denmark }\end{array}$ & & & & $\begin{array}{l}\text { J an 1, 1889- } \\
\text { May } 13,1996\end{array}$ & \\
\hline
\end{tabular}

\subsection{High-water data: Vlissingen, Hoek van Holland, Delfzijl, C uxhaven}

For Cuxhaven, a reconstruction of the astronomical water levels over the period January 1,1843 , to December 31, 1992, is not possible. Too little (observational) information is available to construct an astronomical data set for this station on the basis of the culmination method. Therefore, only the high-water data set of this station is analysed. To provide a basis for comparison, the high-water data sets from Vlissingen, Hoek van Holland and Delfzijl are also analysed.

High-water data sets consist of water levels at hightide, which as for high-water set-up data sets means that in general 2 observations $d^{-1}$ are available. The time periods which are covered by the data sets are given in Table 1.

In general, water levels at high tide have been observed using consistent observation techniques. Factors influencing the homogeneity of the data sets in a negative way (e.g. variation of ordnance datum, registration gaps, etc.) are counteracted. A detailed description of these corrections is given in Dillingh et al. (1993) for the Dutch stations and in J ensen et al. (1992) for Cuxhaven.

The resulting data sets, however, still contain effects which reduce the homogeneity and which have to be ignored in the present study. The most important effects are relative sea level rise (net effect of sea level rise and land subsidence), harbour works and dredging activities. To eliminate these undesirable influences, the long-term trend of the annual mean water level at high tide is subtracted (Bijl 1996). As described in von Storch \& Reichardt (1996), possible creeping inhomogeneities which may arise from a variety of processes, such as relative sea level rise or slow adjustments to (non storm-related) anthropogenic interferences, are averted by this operation.

However, the resulting data sets are not ideal for the present study, because the variation due to astronomical influences (e.g. spring tide-neap tide cycle) is still present. These influences mask the signal which is of most interest in this study. If possible, it would therefore be better to remove the astronomical part (Section 2.1).

\subsection{Daylight high-water data: Delfzijl}

The daylight high-water data set from Delfzijl consists of water levels at the first high tide after $06: 00 \mathrm{~h}$ of each day of the time period. The time period covered by this data set is given in Table 1 .

Before 1882, water levels at high tide were only observed during daylight and in cases of extreme events such as severe storms, providing in general 1 observation $\mathrm{d}^{-1}$. To allow this valuable old data to be used in the present study, the high-water data over the period January 1, 1882, to December 31, 1993, is reduced from 2 observations to 1 observation $\mathrm{d}^{-1}$ by selecting the water level at the first high tide after 06:00 $\mathrm{h}$ of each day. As a result, here it is assumed that the data before and after J anuary 1, 1882, is more or less consistent. The resulting data set is much longer than the high-water and the high-water set-up data sets. However, a disadvantage of this data set is that over the period J anuary 1, 1882, to December 31, 1993, valuable data is omitted. 
With respect to the homogeneity of the data it should be noted that the data before J anuary 1,1882 , is mainly based on visual observations, while afterwards continuous registration equipment was used. However, detailed analysis reveals no systematic differences between the 2 periods (Bijl 1996). As described for the high-water data sets (Section 2.2), other factors influencing the homogeneity of this daylight highwater data set in a negative way are also corrected. The most important correction is the subtraction of the long-term trend of the annual mean water levels at high tide (Bijl 1996). However, the resulting data set still includes variability due to astronomical influences. As outlined for the high-water data sets, this astronomical component masks the signal which is of most interest in this study. Over the complete time period of this data set, however, too little (observational) information is available to construct an astronomical data set on the basis of the culmination method. Therefore, it is not possible to exclude these astronomical influences.

\subsection{M aximum high-water data: Esbjerg}

This data set has been aggregated from hourly readings of water levels of Esbjerg Harbour over the period J anuary 1, 1889, to May 13, 1996 (Table 1), and simply contains the daily maximum water level of 24 hourly readings. Because the remaining 23 hourly readings are not available, no interpolation could be performed in order to approximate the water levels at high tide.

Esbjerg Harbour, founded in 1850, has been subject to successive enlargements which might have influenced the local water levels. Likewise, the inlet to the harbour (which runs between J utland and the Island of Fanoe) has been deepened from about $4.5 \mathrm{~m}$ at the beginning of this century to more than $10 \mathrm{~m}$ now. No systematic investigation of the homogeneity of the data set has been carried out so far. However, experiments with oceanographic models (Danish Hydraulic Institute, 1993) indicate that the high-water levels during westerly storm conditions are rather insensitive to the exact geometry and water depth of the inlet.

Nevertheless, to correct the most important factors decreasing the homogeneity of this maximum highwater data set (see Section 2.2), the long-term trend of the annual mean maximum high-water levels is subtracted (Bijl 1996). Like the high-water data sets, the resulting data set is still influenced by astronomical tidal influences. However, as in the cases of Cuxhaven (high-water data) and Delfzijl (daylight high-water data), a reconstruction of the astronomical water levels is not possible. Therefore, also for this data set the astronomical influences cannot be excluded.

\subsection{H ourly water level data: N ewlyn, Southend}

These sea level data sets contain hourly water levels for each day of the observed period. The time periods which are covered by the data sets are given in Table 1.

A systematic investigation of the homogeneity of the data sets has not been carried out yet. Nevertheless, checks are carried out incorporating error findings, identifying gaps and correcting the data on the basis of gauge operator checks.

In order to remove the undesirable influence of the sample interval of $1 \mathrm{hr}$ (in relation to the time of high tide), a squared spline approximation method (van der Made 1979, de J ong \& Doekes 1983) is applied, providing 'artificial' water levels at high tide for each day of the time period.

Of course, the data sets still include the astronomical tide, which means that astronomical variability is still present (e.g. spring tide-neap tide cycle). However, a reconstruction of the astronomical water levels is not possible, because no observational information is available to construct this data on the basis of the culmination method. This implies that the astronomical part, which masks the signal that is of most interest in this study, cannot be removed from these data sets.

Nevertheless, to correct the most important factors decreasing the homogeneity of these 'artificial' water levels at high tide, the long-term trend of the annual mean 'artificial' water levels at high tide is subtracted (Bijl 1996).

\section{ANALYSIS METHOD}

\subsection{Selection methods}

To put a series of values of a stochastic variable through a statistical (trend) analysis, it is required that these values: (1) come from the same statistical distribution, and (2) are mutually independent. The observational sea level data sets described so far do not completely satisfy these 2 requirements. The main reasons for this are meteorological and hydraulic factors and the deterministic character of the astronomical tide (Dillingh et al. 1993). However, with the help of appropriate selection methods, it is possible to make these data sets suitable for a statistical analysis within the scope of detecting trends and variations in storminess.

To ensure the homogeneity of the data sets, a threshold value and a storm season selection are applied. The threshold value provides the same peak-over-threshold distribution, and the storm season selection (October 1 to $M$ arch 15 ) selects elements of the same (common) distribution (Dillingh et al. 1993). 
In addition, the interdependence (auto-correlation) is suppressed by applying an appropriate selection method in the time domain. Use is made of the DS-i selection method (Dillingh et al. 1993), which requires that each selected element has to be higher than i preceding and $\mathrm{i}$ following elements in the data set. For high-water set-up data, detailed analysis (based on observed auto-correlation) reveals a time window of $2 \mathrm{~d}$ (Dillingh et al. 1993). Because highwater set-up data is available approximately 2 times $\mathrm{d}^{-1}$, this implies $i=4$ is the optimum value. On the basis of this analysis result, the time window for the remaining sea level data sets is also set to $2 \mathrm{~d}$.

\subsection{Q uantile analysis method}

The quantile analysis method is based on a frequency analysis and involves the determination of the roughness/smoothness of succeeding decades in relation to the complete time period of a data set. Possible trends and variations in this decadal quantity are defined by means of linear regression.

This method is developed to take into account all aspects of a selected data set. In essence, this is achieved by taking all data into account in the frequency analysis. The method is characterised by the following steps:

(1) A data set is divided into a sequence of sub-periods. The length of these periods is set to $10 \mathrm{yr}$, mainly because a reliable and robust estimation of exceedance frequencies (Step 2) requires a considerable amount of data.

(2) The following (conditional) 3-parameter Weibull frequency distribution, which approximates exceedance frequency curves above a certain threshold value, is fitted to the data of each $10 \mathrm{yr}$ period and of the complete period:

$$
\mathrm{P}[\mathrm{x}>\mathrm{h} \mid \mathrm{x}>\omega]=\mathrm{e}^{\left(\frac{\mathrm{h}}{\sigma}\right)^{\alpha}+\left(\frac{\omega}{\sigma}\right)^{\alpha}}
$$

where $\mathrm{h}$ is a certain water level (high-water set-up, high-water, etc.), $\alpha$ is the parameter which determines the shape or curvature of the frequency distribution, $\sigma$ is the parameter which determines the scale of the frequency distribution and $\omega$ is the threshold value. So $\mathrm{P}[\mathrm{x}>\mathrm{h} \mid \mathrm{x}>\omega]$ is the chance of exceedance of a certain water level $h$, given a threshold value $\omega$.

In order to create a robust and stable method, 2 of the 3 parameters of this Weibull frequency distribution are pre-defined: the shape or curvature of the distribution, $\alpha$, and the threshold value, $\omega$. With respect to the shape or curvature of the distribution, a fixed $\alpha$ is used. For sea level data sets, detailed analysis reveals $\alpha=1$ (straight line on log-scale) to be the best estimate for this Weibull parameter (Bijl 1996). With respect to the threshold value, $\omega, 3$ ranges of thresholds are used to create a stable and robust method. The bounds of each of the 3 threshold ranges are determined by exceedance frequencies and defined as follows: $1 \mathrm{yr}^{-1}$ to $5 \mathrm{yr}^{-1}$, containing relatively high threshold values; $5 \mathrm{yr}^{-1}$ to $10 \mathrm{yr}^{-1}$, containing medium threshold values; and $10 \mathrm{yr}^{-1}$ to $15 \mathrm{yr}^{-1}$, containing relatively low threshold values.

In Fig. 2, a schematic representation of the estimation of exceedance frequencies of water levels (highwater set-up, high water, etc.) on the basis of the (conditional) 3-parameter Weibull frequency distribution is shown. It should be noted that this figure is an illustration and does not present the results of the study.

(3) On the basis of the 3 defined threshold ranges, $10^{-4}$-quantile values are estimated for both the $10 \mathrm{yr}$ periods and the complete time period of a data set. Several estimates of this quantile value are available, based on the threshold values forming the threshold range which is taken into account. The mean of all these estimates is used as best quantile value. The choice of this $10^{-4}$-quantile value is based on the fact that along the central coast of The Netherlands the safety standard which has been agreed upon has a return period of $10000 \mathrm{yr}$ (which means that once in a lifetime of $100 \mathrm{yr}$ there is a chance of $1 \%$ that flooding will occur; de Ronde et al. 1995).

(4) For each threshold range, the afore-described $10^{-4}$-quantile value of the complete time period of a data set is compared to the $10^{-4}$-quantile values of the $10 \mathrm{yr}$ periods. This provides a measure of the degree of storminess of a selected decade in proportion to the 


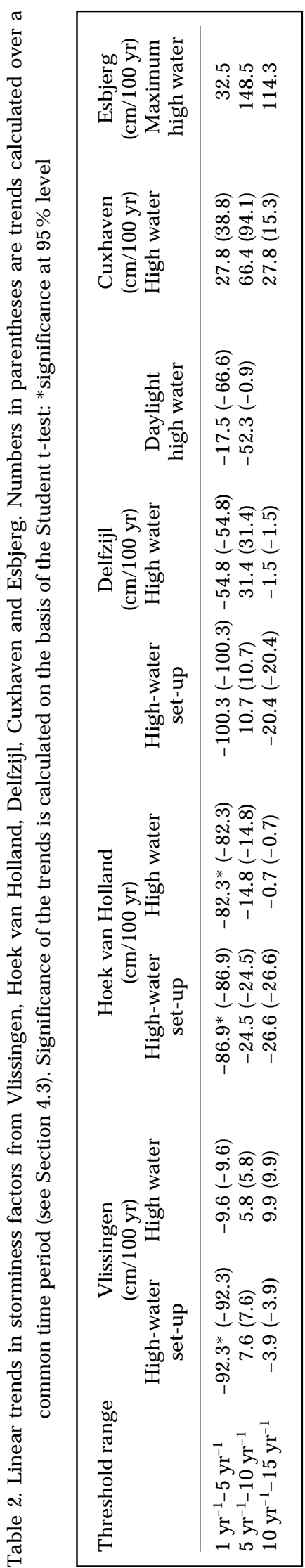

complete time period. For example, if the $10^{-4}$-quantile value of a certain decade is higher than the corresponding quantile value of the complete time period, then it can be argued that this decade has been relatively rough. To quantify this degree of storminess, the difference between the $10^{-4}$-quantile value of the decade and the complete time period is calculated (storminess factor). This means that a positive storminess factor denotes a relatively rough $10 \mathrm{yr}$ period, and a negative storminess factor a relatively smooth period.

(5) The trend in the (decadal) storminess factors is calculated by means of linear regression.

(6) The significance of the calculated trend is calculated on the basis of the broadly known 'Student ttest'. According to Section 3.1, the necessary requirements to apply this test (same [normal] distribution, mutually independent values) are fulfilled. For percentages above $95 \%$, the calculated trend is supposed to be significant. In that case, a continuation of the trend in the future is very likely.

\section{TRENDS AND FLUCTUATIONS}

In this section, the results of applying the quantile analysis method to the selected sea level data sets are presented. In Section 4.1, the preference formulated to correctly interpret these results is described. In Section 4.2 , the analysis results of the individual data sets are described and discussed. In Section 4.3, the emphasis is stressed on an 'area-averaged' interpretation of these results. Finally, Section 4.4 deals with the results of a 'time-shift' variant of the quantile analysis method. This variant is applied to investigate the sensitivity of obtained results with respect to the 'time-position' of the $10 \mathrm{yr}$ periods into which the complete data sets are split up.

\subsection{Preference}

For the Dutch coastal stations Vlissingen, Hoek van Holland and Delfzijl, both (daylight) high-water data and high-water set-up data is available. For the present study, the latter data sets are of particular interest (Section 2.1), because they reflect only storm-related water level fluctuations. Compared to the other sea level data sets available, they are not disturbed by processes unrelated to storm activity, such as local anthropogenic activity (e.g. harbour dredging) or relative sea level rise. Neither do they include astronomical tidal influences (e.g. spring tide-neap tide cycle), which also induce a non storm-related signal. Therefore, in this section, the analysis will mainly be concentrated on the high-water set-up data sets. 


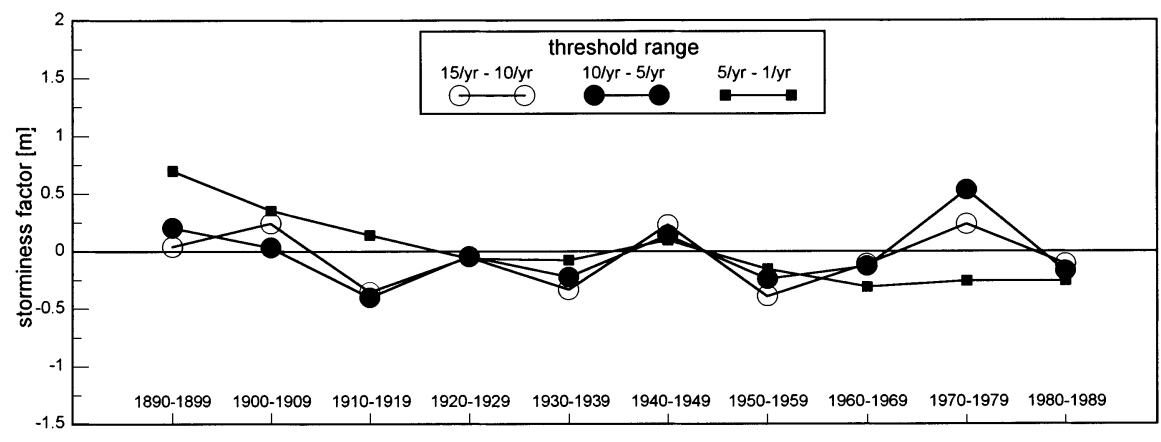

Fig. 3. Fluctuations in the (decadal) high-water set-up storminess factors from $\mathrm{V}$ lissingen

\subsection{Individual data sets}

\subsubsection{Vlissingen}

Fig. 3 shows fluctuations in the (decadal) high-water set-up storminess factors from $\mathrm{V}$ lissingen calculated on the basis of the quantile analysis method. These results show small to moderate inter-decadal variability. Trend lines indicate a tendency towards a small decrease in storminess (Table 2), whereby in the case of the $1 \mathrm{yr}^{-1}$ to $5 \mathrm{yr}^{-1}$ threshold range this decrease is significant. The latter can mainly be attributed to relatively large positive storminess factors in the decades around 1900. These relatively high storminess factors are also apparent in the analysis results of the highwater set-up data sets from Hoek van Holland and Delfzijl, and in the high-water data sets from these 3 Dutch coastal stations. For Delfzijl, the daylight highwater data set also shows this feature.

The magnitude of the calculated trends is remarkably large. This can be explained by the fact that the trend calculation is based on very small exceedance frequencies (Section 3.2). A pplying the quantile analysis method (Step 3) on the basis of higher exceedance frequencies (e.g. a $10^{-1}$-quantile value) would give magnitudes of trends which are comparable to those cited in the literature for N orth-West Europe.

Analysis results of the highwater data set from Vlissingen do not completely support those of the high-water set-up data set. Although they also show moderate inter-decadal variability, the calculated linear trends (small, not significant) are both increasing and decreasing. The main explanation for this phenomenon is the fact that this high-water data set still contains deterministic astronomical tidal influences (e.g. the spring tide- neap tide cycle).

\subsubsection{Hoek van Holland}

The results of the quantile analysis method based on the high-water set-up data set from Hoek van Holland are quite similar to those based on the high-water setup data set from Vlissingen; small to moderate interdecadal variability (Fig. 4.). Trend lines show a clear tendency towards a decrease in storminess (Table 2), whereby in the case of the $1 \mathrm{yr}^{-1}$ to $5 \mathrm{yr}^{-1}$ threshold range this decrease is significant. As for Vlissingen, this decrease can be attributed to relatively large positive storminess factors in the decades around 1900.

The analysis results of the high-water data set support the afore-described results. Important to note is that this high-water data set also shows a significant decrease in storminess for the $1 \mathrm{yr}^{-1}$ to $5 \mathrm{yr}^{-1}$ threshold range.

\subsubsection{Delfzijl}

Fluctuations in the storminess factors of the highwater set-up data set from Delfzijl are shown in Fig. 5. Based on the quantile analysis method, the results show moderate to large variability on a decadal time scale. The calculated trends are both increasing and decreasing (Table 2). Therefore, it is remarkable that

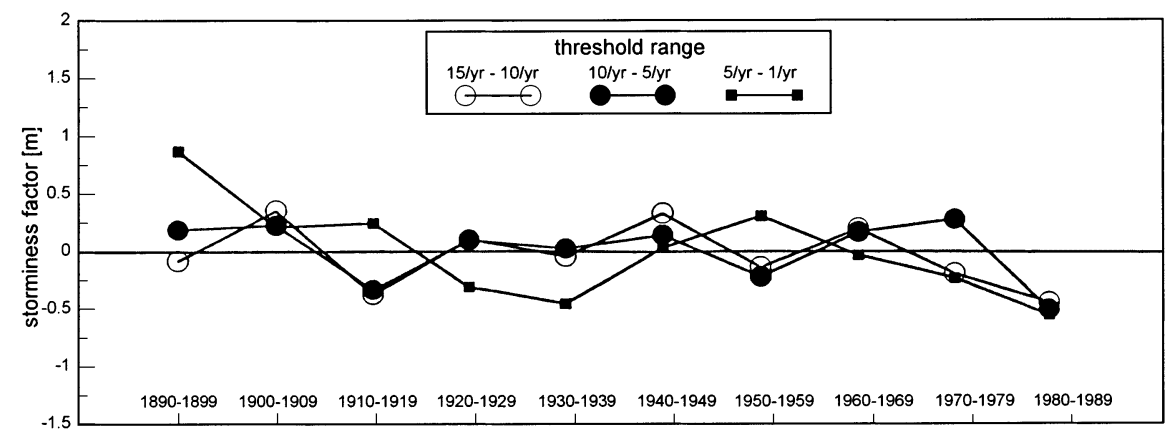

Fig. 4. Fluctuations in the (decadal) high-water set-up storminess factors from Hoek van Holland 


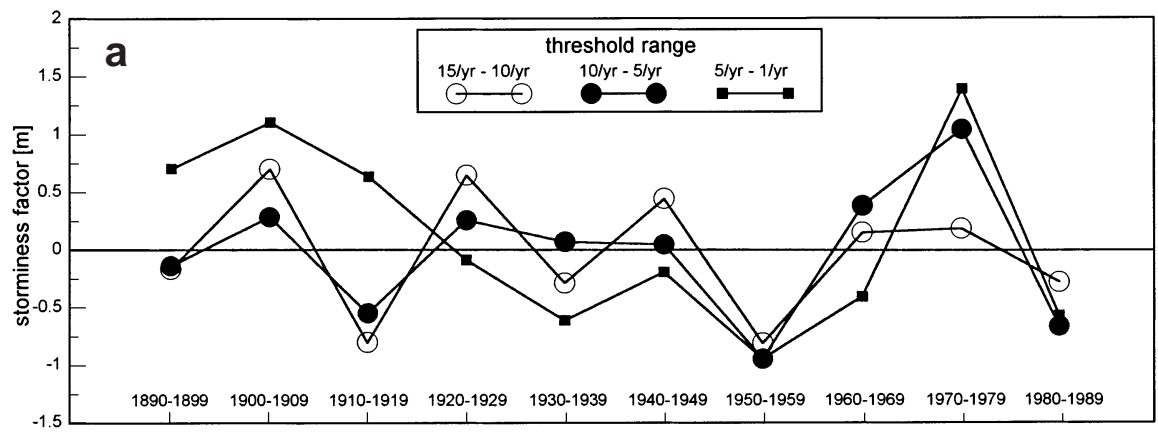

Fig. 5. Fluctuations in the (decadal) (a) high-water set-up and (b) (daylight) high-water storminess factors from Delfzijl

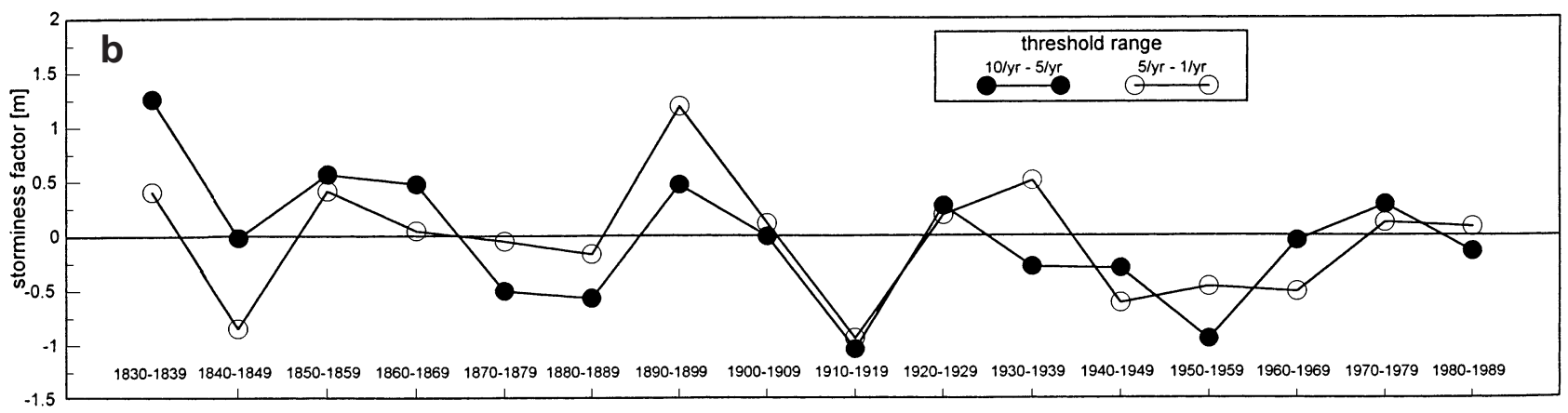

the calculated trend in the case of the $1 \mathrm{yr}^{-1}$ to $5 \mathrm{yr}^{-1}$ threshold range is strongly decreasing (not significantly). As for Vlissingen and Hoek van Holland, this can be attributed to relatively large positive storminess factors in the decades around 1900.

The analysis results of the high-water data set support the results described above. One difference is that the trend calculated on the basis of the $1 \mathrm{yr}^{-1}$ to $5 \mathrm{yr}^{-1}$ threshold range for the high-water data shows a reduced decrease in storminess.

Results of the quantile analysis method based on the daylight high-water data set also show relatively large variability at a decadal time scale. All calculated trends are, however, decreasing (not significantly), which can mainly be attributed to the decades 1830-1839 and 1890-1899 (Fig. 5).

\subsubsection{Cuxhaven}

The results based on the high-water data set from Cuxhaven (Fig. 6) show relatively large fluctuations on a decadal time scale. All linear trends calculated on the basis of the quantile analysis method are, however, increasing (not significantly). These increases can mainly be attributed to the very large positive stormi-

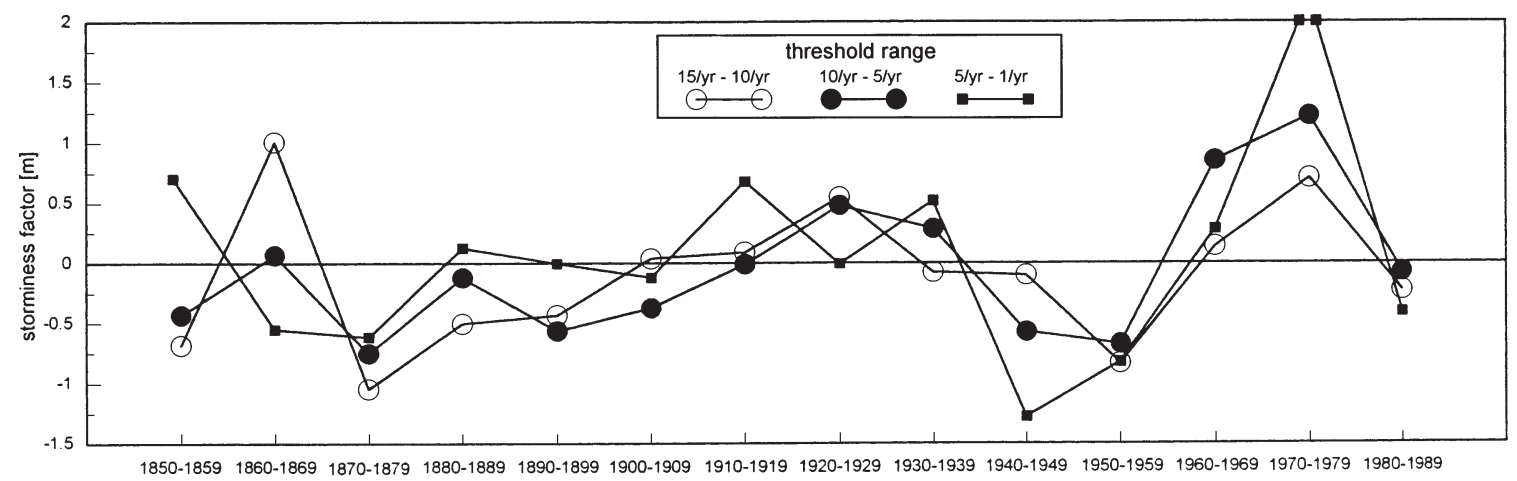

Fig. 6. Fluctuations in the (decadal) high-water storminess factors from Cuxhaven 
Fig. 7. Fluctuations in the (a) preliminary analysis method $2 \mathrm{yr}$ quantities (max., max.-5, max.-10, max.-20: highest and fifth, tenth and twentieth highest values of the sorted $2 \mathrm{yr}$ data) and (b) (decadal) high-water storminess factors from Esbjerg. Dotted line: note the absence of maximum values above $3 \mathrm{~m}$ before 1910
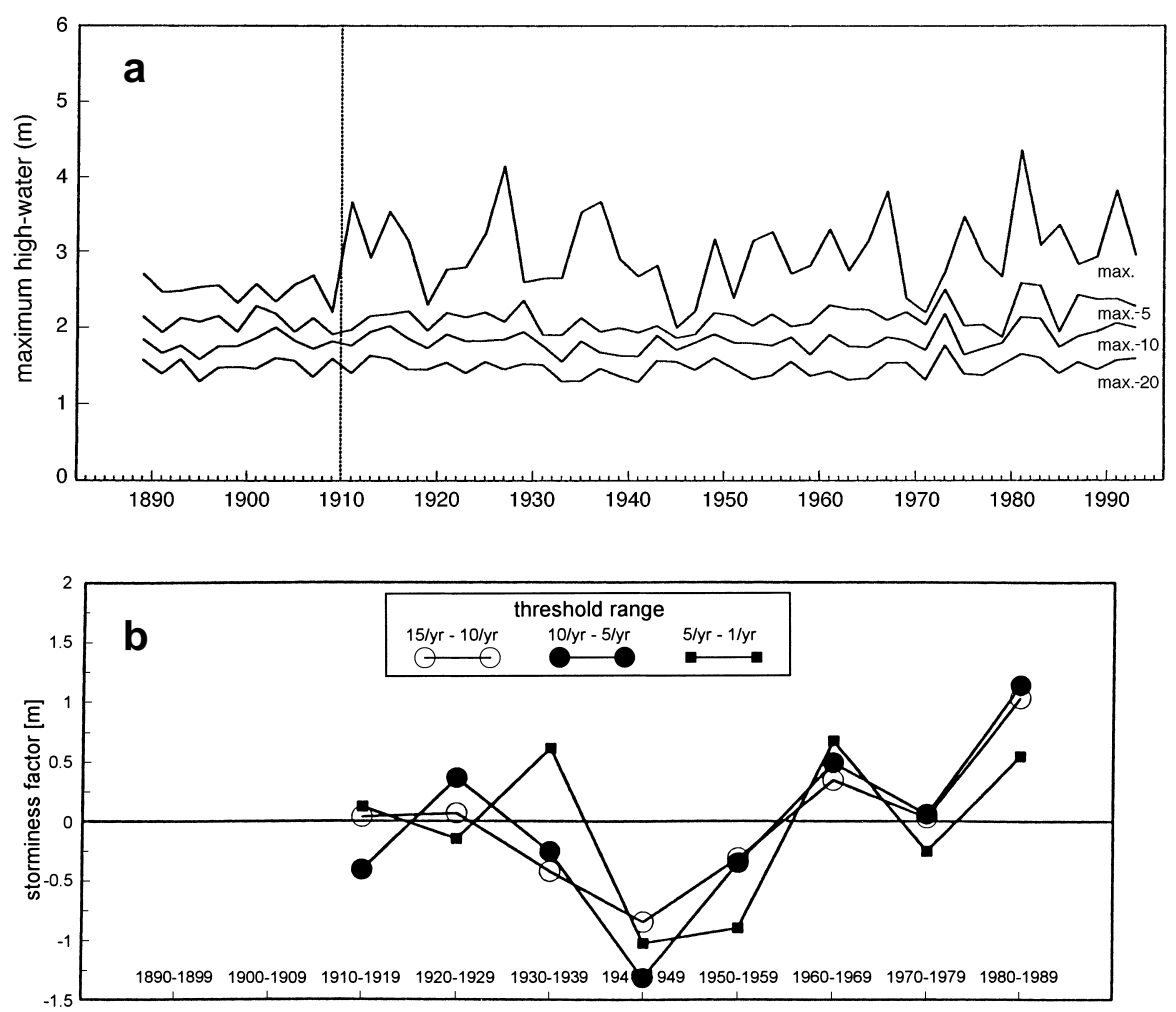

ness factor in the 1970s, which is also apparent in the quantile analysis results of the high-water and highwater set-up data set from Delfzijl.

\subsubsection{Esbjerg}

In Fig. 7a, the results of a preliminary analysis method applied to the maximum high-water data set from Esbjerg are shown. In fact, this preliminary analysis method was applied to all data sets described in this section, mainly to get a first quick indication of the data sets. The method involves the detection of the following $2 \mathrm{yr}$ quantities: maximum, highest value of the sorted 2 yr data; maximum-5, fifth highest value of the sorted 2 yr data; maximum-10, tenth highest value of the sorted $2 \mathrm{yr}$ data; and maximum-20, twentieth highest value of the sorted $2 \mathrm{yr}$ data. Only for Esbjerg are the results of this rather straightforward analysis method rather remarkable. The striking feature of these results is the absence of maximum values above $3 \mathrm{~m}$ before 1910 (Fig. 7a). Up to now, it has not been possible to explain this feature, although it is clear that such an abrupt jump cannot be attributed to natural phenomena. This is supported by the fact that the jump is not apparent in the maximum-5, maximum- 10 and the maximum- 20 curves.

Confining the analysis to the period 1910 and onwards, the results of the quantile analysis method show relatively large variability at a decadal time scale (Fig. 7b). All calculated linear trends are increasing (not significantly). As in the case of the analysis results of the high-water data sets from Delfzijl and Cuxhaven, this can mainly be attributed to relatively large storminess factors in the past decades (1960-1989).

\subsubsection{Newlyn}

A nalysis results based on the sea level data set from Newlyn ('artificial' water levels at high-tide, calculated on the basis of hourly readings) show little natural variability at a decadal time scale. Due to the relatively short timespan of the data set, the number of storminess factors which are generated on the basis of the quantile analysis method is relatively small. In fact, a reliable trend calculation could not be performed. Therefore, the main conclusion which is drawn from the analysis results from Newlyn is that the interdecadal natural variability over the period 1920-1989 is relatively small.

\subsubsection{Southend}

As in the case of the sea level data set from Newlyn, the analysis results from Southend also show little natural variability at a decadal time scale (Fig. 8). It is 


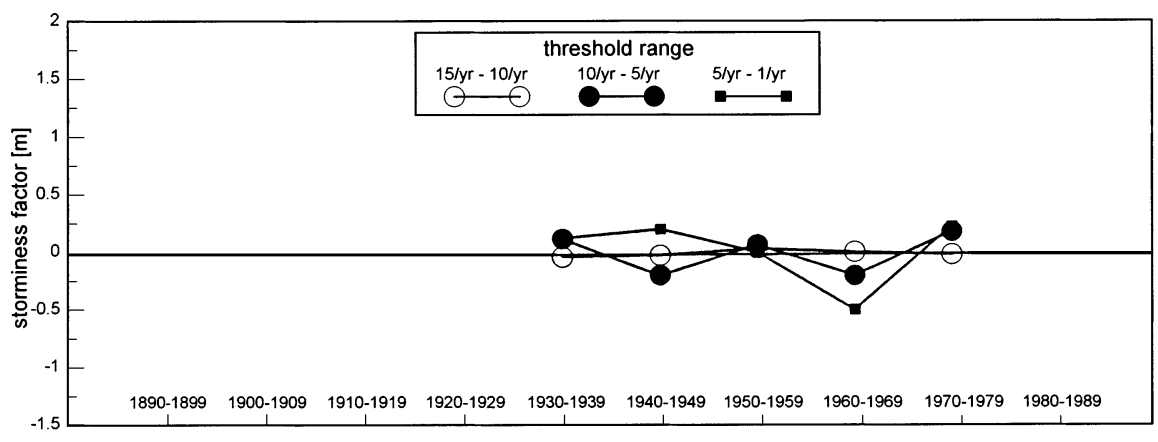

Fig. 8. Fluctuations in the decadal (artificial) high-water storminess factors from Southend obvious that the timespan of this data set ('artificial' water levels at high-tide, calculated on the basis of hourly readings) is too short for a successful trend analysis on the basis of the calculated storminess factors. Within the context of the present study, the main conclusion to be drawn from this data set is therefore that the inter-decadal natural variability over the period $1930-1979$ is relatively small.

\subsection{Area-averaged interpretation}

The analysis results, described in Section 4.2, are based on a linear trend calculation over the complete time period of the individual data sets. However, to compare variability and trends in storminess from different locations within an area, it is better to use a common time period. Therefore, besides a trend analysis over the complete time period of each individual data set, a trend calculation is also performed over a common time period. Due to the aim of the present study (detection of long-term trends and variation in storminess), the common time period is set to the period J anuary 1,1889 , to December 31, 1992. However, this means that the sea level data sets from Newlyn, Southend and Esbjerg are not taken into consideration in the trend analysis. Thus, the benefit of this common time period must be seriously considered in relation to the disadvantage of omitting valuable data.

Over the common time period, the quantile analysis results of the high-water set-up data sets (Table 2, in parentheses) indicate a tendency towards a decreasing trend in storminess for the more southern Dutch coastal stations (Vlissingen, Hoek van Holland). Most of the calculated trends are negligibly small or decreasing, whereby in case of the $1 \mathrm{yr}^{-1}$ to $5 \mathrm{yr}^{-1}$ threshold range this decrease is even significant. The analysis results for the more northern station Delfzijl are not so consistent; they show both increasing and decreasing trends (not significant). The difference between the southern stations and the northern station Delfzijl described above is also noticeable when the variability at a decadal time scale is taken into consideration; the analysis results of the more southern stations Vlissingen and Hoek van Holland show less natural variability than those of the northern station Delfzijl.

The results based on the high-water data sets over the common time period do not completely support the results described above. Although the results of the southern stations (Vlissingen and Hoek van Holland) also feature less variability at relatively short time scales than the results of the northern stations Delfzijl and Cuxhaven, in general the sign of the calculated trends for Vlissingen, Hoek van Holland, Delfzijl and Cuxhaven is much more variable. A possible explanation for this fluctuating behaviour is that these highwater data sets still contain undesirable astronomical tidal influences which mask the signal that is of most interest in this study. This might also be true for the daylight high-water data set from Delfzijl. The results based on this data set show decreasing trends (not significant) in storminess over the common time period. However, the variability at a decadal time scale is relatively large.

As a result, it can be concluded that the 'observed' distinction between the northern and southern stations is not clearly noticeable in data sets which do not purely reflect storm-related water level fluctuations. The exception which proves the 'rule' is the highwater data set from Cuxhaven. The results based on this data set clearly show a tendency towards an increase in storminess (not significant) over the common time period.

\subsection{Sensitivity}

To investigate the sensitivity of the quantile analysis method to the selection of the $10 \mathrm{yr}$ periods in which the complete data sets are split up, a 'time shift' variant of this method is developed. This variant involves splitting the complete data sets up into successive decades which, compared to the decades used in the original method, are shifted $5 \mathrm{yr}$ in time. In this way, the impact of the 'time position' of the chosen decades is examined. 
The analysis results of this variant of the quantile analysis method reveal no fundamental differences (Table 3). Although there are some differences in sign and magnitude of the calculated trends, in essence the results also indicate a tendency towards a small (not significant) weakening of the storm climate for the more southern stations (V lissingen, Hoek van Holland) and a negligible to small (not significant) worsening for more northern stations (Delfzijl, Cuxhaven, Esbjerg). The high-water set-up data sets, which purely reflect the storm-related water level fluctuations, especially suggest this dichotomy.

In addition to the time-shift variant of the quantile analysis method, the sensitivity of the storminess factors with respect to the length of the time period in which a complete data set is split up was also investigated. Therefore, a $2 \mathrm{yr}$ variant of the quantile analysis method was developed, which means that a data set is divided into a sequence of $2 \mathrm{yr}$ periods. The major disadvantage of this method is, however, that the applied threshold ranges contain less threshold values than wished, especially the $1 \mathrm{yr}^{-1}$ to $5 \mathrm{yr}^{-1}$ threshold range.

The analysis results of this second variant of the quantile analysis method reveal no fundamental differences. Although there are some differences in sign and magnitude of the calculated trends, in essence this $2 \mathrm{yr}$ variant indicates the same trends as the original method.

\section{DISCUSSION AND CONCLUSIONS}

The aim of the present paper is to detect any sign of changing storminess in long-term observational sea level data sets in North-West Europe. In this final section, some discussion and concluding remarks are made on the factors which play important roles in this topic.

\subsection{Data}

In North-West Europe, in principle, a large number of long-term observational sea level data sets is available. However, many of these data sets suffer from inhomogeneity. Except for the high-water set-up data sets, most of these data sets reflect the impacts of external factors such as relative sea level rise, effect of harbour works or dredging activities on the astronomical tide. As a result, the number of long-term observational data sets which only reflect storm-related variations is quite small.

The present paper deals with sea level data sets which have been corrected as much as possible for factors influencing the homogeneity in a negative way.

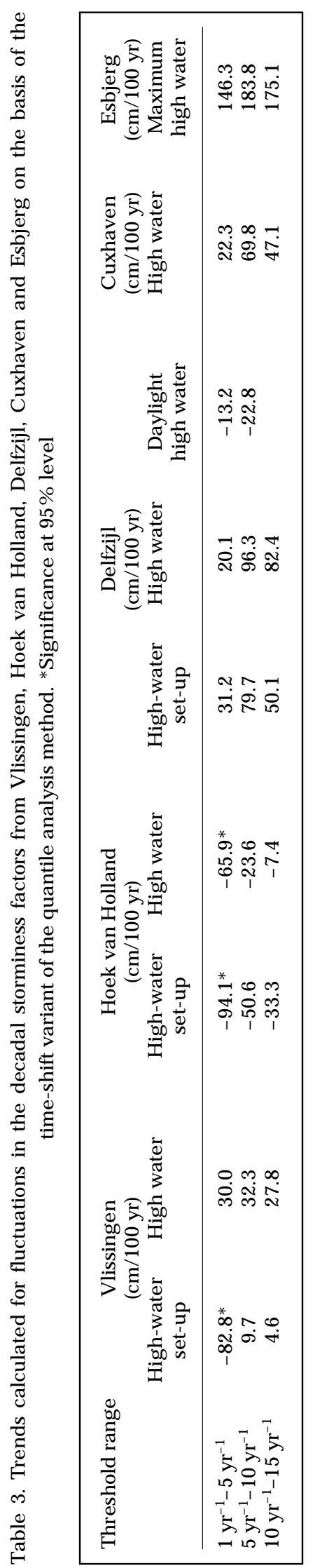


The most attention is paid to the high-water set-up data sets, because these data sets reflect only stormrelated water level fluctuations. Compared to the other data sets available, these data sets are not disturbed by processes unrelated to storm activity and do not reflect the undesirable variety due to astronomical influences. Within the perspective of the present paper these data sets are therefore of most interest.

\subsection{Trends and fluctuations}

The analysis results of the sea level data sets described in the present paper can be considered in 2 ways: local and area-averaged.

\subsubsection{Local results}

It can be concluded that, when more than 1 sea level data set per station is available, the quantile analysis results reveal that there is not always consistency in sign and magnitude of the calculated trends per station. A possible explanation for this phenomenon is that most of the analysed data sets (high-water, maximum high-water and daylight high-water data sets) still contain undesirable astronomical tidal influences, which mask the signal that is of most interest in this study. This is supported by the fact that the analysis results of the high-water set-up data sets, which only reflect storm-related water level fluctuations, are much more consistent.

\subsubsection{Area-averaged results}

In general, it can be stated that the quantile analysis results show that, although there is considerable natural variability at a decadal time scale (especially for the more northern stations), over the complete time period of the analysed data sets no sign of a significant increase in storminess over North-West Europe is detected.

The results indicate a distinction between stations in the German Bight and stations in the southern part of the North Sea. In the latter area, all results show a small to moderate natural variability at a decadal time scale. However, in the German Bight this variability is clearly more enhanced. This 'distinction' between southern and northern stations is also noticeable when the results of the (linear) trend calculation are taken into consideration. The high-water set-up data sets, which are not disturbed by processes unrelated to storm activity, especially show this dichotomy.
Although sign and magnitude of the calculated trends are not entirely unequivocal, for sea level stations in the southern North Sea there seems to be a tendency towards a small weakening of the storm climate over the past $100 \mathrm{yr}$. This is supported by the fact that, in this study, significant (downward) trends were only calculated for stations in this area (Table 2). Trends calculated for the more northern stations in the German Bight show, however, no indication of a weakening of the storm climate. Though not significantly, in fact they show mostly increasing trends.

\section{LITERATURE CITED}

Bijl W (1996) Looking for observational signs of 'changing storminess'. Rijkswaterstaat, National Institute for Coastal and Marine Management, The Hague, report no. RIKZI OS-96.157x

Carter DJT, Draper L (1988) Has the North-East Atlantic become rougher? Nature 332:494

Danish Hydraulic Institute (1993) Gradybundersogelsen 1992, Kyst-Havnesarnarbejdets Forlag. Danish Hydraulic Institute, Lemvig

de J ong RE, Doekes J (1983) Vergelijking d.m.v. HARBEK10 berekende extrema met waarnemingen. Rijkswaterstaat, Direktie Waterhuishouding en Waterbeweging, The Hague, report no. KD 83.02

de Ronde J G (1984) Correcties t.b.v. de Getijtafels voor Nederland 1985. Rijkswaterstaat, National Institute for Coastal and $M$ arine $M$ anagement, The Hague, report no. WW-WH 84.05

de Ronde J G, Dillingh D, Philippart ME (1995) Design criteria along the Dutch coast. Proceedings of the international workshop on water related problems in low-lying coastal areas, HYDROCOAST 95, Bangkok, p 130-151

Dillingh $D$, de Haan L, Helmers R, Können GP, van Malde J (1993) De basispeilen langs de Nederlandse kust, Statisch onderzoek. Rijkswaterstaat, Tidal Water Division/National Institute for Coastal and Marine Management, The Hague, report no. DGW-93.023

Hogben N (1995) Increases in wave heights over the North Atlantic: a review of the evidence and some implications for the naval architect. Trans R Inst Naval Architects 137: 93-115

J ensen J , M ügge H, Schönfeld W (1992) Analyse der Wasserstandsentwicklung und Tidedynamik in der Deutschen Bucht. Die Küste 53:211-275

Leggett J (1993) Climate change and the insurance industry: solidarity among the risk community? Greenpeace International

van der Made J W (1979) Interpolatie-technieken voor waterstandsverhanglijnen. Rijkswaterstaat, Direktie Waterhuishouding en Waterbeweging, The Hague, report no. WW-WH-78.05

van Hooff RW (1994) Trends in the wave climate of the Atlantic and the North Sea: evidence and implications. Underw Technol 19:20-23

von Storch H, Reichardt H (1996) A scenario of storm surge statistics for the German Bight at the expected time of doubled atmospheric carbon dioxide concentration. GKSS Research Centre, Institute of Hydrophysics, Geesthacht, report no. GKSS 96/E/18

Submitted: J anuary 23, 1998; Accepted: August 20, 1998

Proofs received from author(s): J anuary 20, 1999 